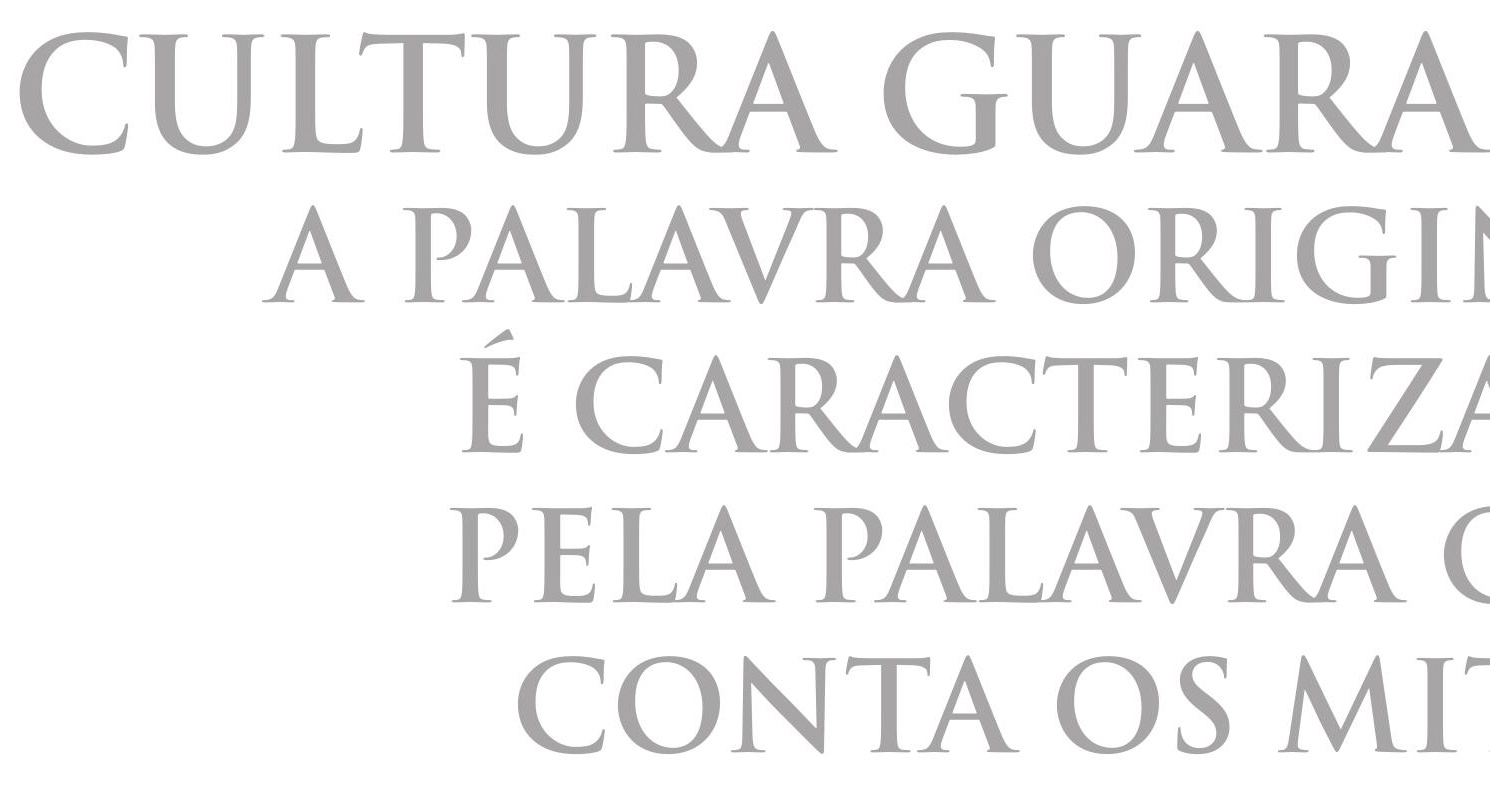




\section{CULTURA GUARANI: A PALAVRA ORIGINAL É CARACTERIZADA PELA PALAVRA QUE CONTA OS MITOS}




\title{
CULTURA GUARANI: A PALAVRA ORIGINAL É CARACTERI- ZADA PELA PALAVRA QUE CONTA OS MITOS
}

\section{Resumo}

O objetivo Geral da análise é a captação das linhas gerais da discussão acerca da cultura Guarani em seus traços mais característicos como a linguagem, a religião e o sonho. A metodologia da pesquisa foi efetivada através da coleta de dados a partir de fontes primárias e secundárias. A delimitação temporal abrangeu desde a chegada dos jesuítas no Paraguai em 1558, até a sua expulsão das possessões espanholas em 1767. A opção teórica metodológica visou conferir historicidade ao objeto, buscando-se fugir da abordagem dominante. Ao dar historicidade ao objeto impôs a análise desvendar as contradições e os antagonismos resultantes da conquista europeia. Concluímos que a palavra, a terra, o sonho e a religião não se explicam por si só, porém, são elementos essenciais que possibilitam entender as teias de relações sociais desenvolvidas historicamente. Desvelamos que nada do que pertence à cultura pode ser estanque, porque ela se insere em uma realidade onde a mudança é um aspecto fundamental.

Palavras-chave: Cultura, Guarani, História.

\section{GUARANI CULTURE: THE ORIGINAL WORD IS CHARACTERI- ZED BY THE WORD THAT TELLS THE MYTHS}

\begin{abstract}
The main objective of the analysis is to capture the general discussion about the Guarani culture in its most characteristic features such as language, religion and dream. The research methodology was carried out by collecting data from primary and secondary sources. The temporal boundary covered since the arrival of the Jesuits in Paraguay in 1558 until their expulsion of the Spanish possessions in 1767. The theoretical and methodological approach aimed at giving historicity to the object, seeking to escape the dominant approach. By lending historicity to the object we imposed to the analysis the unravelling of contradictions and antagonisms resulting from the European conquest. We conclude that
\end{abstract}


the word, the earth, the dream and the religion cannot be explained by themselves, however, they are essential elements that make possible to understand the web of social relations historically developed. We unveil that nothing that belongs to culture can be sealed because it is part of a reality where change is a key issue.

Keywords: Culture, Guarani, history.

\section{CULTURA GUARANI: LA PALABRA ORIGINAL ES CARACTE- RIZADA POR LA PALABRA QUE CUENTA LOS MITOS}

\section{Resumen}

El objetivo general del análisis es captar las líneas generales de la discusión sobre cultura guaraní en sus rasgos más característicos, tales como el lenguaje, la religión y el sueño. La metodología de investigación se llevó a cabo mediante la recopilación de datos de fuentes primarias y secundarias. La delimitación temporal abarca desde la llegada de los jesuitas a Paraguay en 1558, hasta su expulsión de las posesiones españolas en 1767. El enfoque teórico y metodológico buscó conferir historicidad al objeto, intentando escapar de un enfoque dominante. Al dar historicidad al objeto, el análisis busca desentrañar las contradicciones y antagonismos resultantes de la conquista europea. Concluimos que la palabra, la tierra, el sueño y la religión guaraní no se pueden explicar por sí solos, sin embargo, son elementos esenciales que posibilitan comprender los entramados de las relaciones sociales desarrolladas históricamente. Revelamos que nada perteneciente a la cultura puede ser estático, pues esta es parte de una realidad donde el cambio es una cuestión fundamental.

Palabras Clave: Cultura, Guaraníes, Historia.

Endereço do autor para correspondencia: Rua: Floriano Paula Corrêa, 555. Campo Grande / MS. CEP: 79081-400.

silvinoareco@yahoo.com.br 


\section{INTRODUÇÃO}

De acordo com Melià (1991), quando da invasão dos espanhóis e dos portugueses na América, por volta de 1500, os índios da etnia Guarani já formavam um conjunto de povos com a mesma origem, falavam um mesmo idioma, haviam desenvolvido um "modo de ser" que mantinha viva a memória de antigas tradições e se projetavam para o futuro, praticando uma agricultura muito produtiva.

Essa prática agrícola gerava amplos excedentes, que motivavam grandes festas e a distribuição dos produtos, conforme determinava a economia da reciprocidade. Quando os europeus chegaram ao lugar, que hoje é a cidade de Assunção, atual capital do Paraguai, ficaram maravilhados com a "divina abundância" que encontraram. Passados vários séculos, encontramos apenas parcas reminiscências desse passado, os nativos tiveram suas terras invadidas, passaram por um verdadeiro genocídio, sua cultura sofreu um processo brutal de subjugação frente à cultura dominante. Os conquistadores tentaram lhes impor uma nova língua, uma nova religião, um novo "modo de ser". Porém, a cultura guarani resiste até hoje, seguindo nessa direção a finalidade do artigo é resgatar e apresentar alguns elementos dessa cultura.

O objetivo Geral da análise é a captação das linhas gerais da discussão acerca da cultura Guarani, em seus traços mais característicos, como a linguagem, a religião e o sonho.

$\mathrm{O}$ estudo tem um caráter histórico e antropológico, buscamos na aprecia- ção resgatar a compreensão de como se deu a síntese por incorporação da cultura Guarani com a cultura do conquistador europeu. Esse procedimento metodológico permitiu efetuar a síntese dialética dos aspectos objetivos e subjetivos que teceram a trama do tecido social instituído no Paraguai Colonial. A aproximação em relação aos aspectos culturais, sociais e antropológicos da referida etnia propiciará uma melhor compreensão das relações sociais empreendidas entre os jesuítas ${ }^{1}$, os guaranis e os colonizadores na Província do Paraguai (1558-1767).

A delimitação temporal abrangeu desde a chegada dos jesuítas no Paraguai em 1558, até a sua expulsão das possessões espanholas em 1767. A metodologia da pesquisa foi efetivada através da coleta de dados a partir de fontes primárias e secundárias. A delimitação espacial do estudo se prendeu à Província do Paraguai .

A opção teórica metodológica visou conferir historicidade ao objeto, buscando-se fugir da abordagem dominante. Ao dar historicidade ao objeto impôs a análise desvendar as contradições e os antagonismos resultantes da conquista europeia. Por conseguinte, descrever as particularidades das relações sociais que foram sendo construídas no espaço geográfico delimitado.

Quanto ao arcabouço do trabalho, este apresenta: a introdução no qual expomos o tema, a metodologia, a fonte dos dados e a estrutura do trabalho. No primeiro capítulo fazemos uma retrospectiva histórica da etnia supracitada. No segundo capítulo reconstituímos 
o processo da dominação colonial. No terceiro capítulo analisamos o processo de aculturação empreendido pelos colonizadores, que buscaram substituir a cultura originária dos guaranis pela cultura europeia. O conceito de aculturação ${ }^{3}$ tem o sentido explicitado por Cuche (2002:114): “A aculturação é o conjunto de fenômenos que resultam de um contato contínuo e direto entre grupos de indivíduos de culturas diferentes e que provocam mudanças nos modelos (patterns) culturais iniciais de um ou dos dois grupos. "

Nas considerações finais, apontamos que o esforço de captação das linhas gerais da discussão acerca da cultura Guarani, em seus traços mais característicos, a linguagem, a religião e o sonho, decorrem no sentido de pensarmos em cultura como dimensão dinâmica do processo social.

\section{A MIGRAÇÃO COMO HISTÓRIA}

Melià (1991) esclarece que o tupi-guarani, como linguagem e como cultura é um ramo do tronco linguístico tupi mais antigo, a partir do qual tomou características próprias e diferenciadas, provavelmente, desde o primeiro milênio antes de Cristo, aproximadamente de 3.000 a 2.500 anos atrás. De acordo com o autor, os guaranis migraram da bacia amazônica hipoteticamente motivada por um notável aumento demográfico, intensificado em um período que coincide com o período da cultura ocidental de aproximadamente 2.000 anos.

O autor descreve que os grupos étnicos, denominados atualmente de
Guarani, passaram a ocupar as selvas subtropicais do Alto-Paraná, do Paraguai e do médio Uruguai. Esses povos se locomoviam de um lugar para outro em busca de novas terras, porém, não eram nômades que dependiam impreterivelmente da caça, da pesca e da coleta para a produção e reprodução de suas existências. Eram, acima de tudo, agricultores que sabiam explorar eficazmente as terras selvagens, cujas árvores derrubavam e queimavam, na qual plantavam mandioca, legumes, etc. Os indígenas da etnia Guarani eram extremamente hábeis na arte da cerâmica, os artefatos produzidos eram utilizados para preparar e servir seus alimentos. Como colonos dinâmicos continuaram a sua expansão migratória, até aos tempos da invasão europeia, no Rio da Prata (na década de 1520). De acordo com Melià (1991), a migração como história e como projeto constitui uma das marcas características desse povo, ainda que muitos de seus grupos tenham permanecido por séculos num mesmo território e nunca tenham feito uma migração efetiva.

Melià (1991:14) afirma que, o mito guarani da busca da "terra sem mal" e de uma "terra nova" são estruturas marcantes de seu pensamento e de sua vivência; na realidade, a "terra sem mal" é uma síntese histórica e prática de uma economia vivida profeticamente. Melià (1991:14) esclarece: “[...] Animicamente el Guaraní es un pueblo en éxodo, aunque no desenraizado, ya que la tierra que busca es la que le sirve de base ecológica, hoy como en tiempos pasados y como será mañana". 
Melià (1991) afirma que ao longo dos últimos 1500 anos, período em que as tribos podem considerar-se formadas com suas características próprias, os guaranis têm se mostrado fiéis a sua cultura original, não por inércia, mas pelo trabalho ativo na busca das condições ambientais mais adequadas para o desenvolvimento de seu modo de ser. De acordo com Melià (1997:15): "La tradición en este caso es profecía viva. La búsqueda de 'la tierra sin mal' como estructura del modo de pensar de Guaraní, informa el dinamismo económico y la vivencia religiosa, que le son tan propias".

No capítulo seguinte vamos verificar como se deu o processo de dominação colonial.

\section{DOMINAÇÃO COLONIAL}

Com a invasão espanhola nos séculos $\mathrm{XVI}^{4}$, os colonos na medida em que avançaram no território no século XVII, em suas viagens de exploração ou em suas expedições de conquistas foram acompanhados dos missionários, principalmente jesuítas em sua "conquista espiritual".

Naquele contexto social e histórico, os europeus encontraram os nativos da etnia Guarani organizados, formando conjuntos territoriais mais ou menos extensos, que os colonizadores denominaram de "províncias". Estas eram reconhecidas pelos nomes próprios dos grupos indígenas que ali habitavam: Cário, Tobatín, Guaramboré, Itatin, Mbaracayú, gente del Guairá, del Paraná, del Uruguai, los del Tape.
As províncias abarcavam um vasto território, que ia da costa do Atlântico ao sul de São Vicente até a margem direita do Rio Paraná, desde o sul do Rio Paranapanema e do Grande Pantanal (o lago de Los Jarayes) até as ilhas do delta, junto a Buenos Aires. Melià (1991) esclarece que por sobre as denominações particulares prevaleceu, entre os colonizadores, o nome genérico de Guarani para denominar os originários dessa região. Esse fato ocorreu, possivelmente, devido à unidade linguística dos dialetos dos grupos e a profunda semelhança em sua organização sociopolítica, também devido as similaridades de suas expressões culturais. Nesse sentido, Melià (1991:15) traz a seguinte explicação:

Lo Guaraní era la "Lengua General" de gentes que cubrían una amplísima geografía. Debe tenerse en cuenta, sin embargo, que en ese espacio estaban enclavados otras "naciones", generalmente pobladores más antiguos, con áreas de ocupación bastante desigual y con relaciones más o menos conflictivas con los guaranís.

Melià (1991) esclarece que na época dos primeiros contatos com os europeus, a população de originários alcançava cifras consideráveis. A hipótese de uma população de aproximadamente 1 500000 até 2000000 (dois milhões) de indivíduos. Ainda que pareça forte e superestimada, esses dados sobre o contingente populacional, tal informação parte de um fundamento sério, que se repousa na documentação histórica. Essa projeção se torna plausível e ganha veracidade quando se considera a boa produtividade que alcançava os 
grupos neolíticos com sua economia baseada na reciprocidade, essa práxis social estava ligada umbilicalmente com a crença religiosa. Durante o período colonial, a queda no censo demográfico alarmou os governadores espanhóis (adelantados) das províncias.

Naquele contexto histórico, foi detectado pelas autoridades colôniais que províncias inteiras haviam desparecido ou ficaram subjugadas pelos encomenderos $^{5}$. As aldeias indígenas e as reduções jesuíticas sofriam ataques constantes dos bandeirantes paulistas em busca de escravos.

Outro fator que contribuiu para a queda demográfica nessa região, de acordo com centenas de relatos, foram as doenças trazidas pelos brancos que dizimaram grandes contingentes indígenas. Sobre o genocídio dos nativos, Melià (1991:16) afirma que: "La Provincia Del Guairá, por ejemplo, que contó con más de 200000 indios (y tal vez hasta 800.000 ), fue reducida a prácticamente ningún habitante. La mayor parte de esta gente se han muerto de pestilencia, malos tratamiento y guerras $[\ldots .$. ".

Melià (1991) afirma que milhares de índios da etnia Guarani foram absorvidos pela mestiçagem biológica e social, entretanto, outros milhares foram reduzidos em missões franciscanas (desde 1580) e jesuítas (desde 1605). Melià (1991:16) afirma que quando esses povos foram desintegrados enquanto grupos ao longo do século XIX: “[...] Sus pobladores tornaran se miembros del nuevo Estado Paraguayo que los asimilaba y les imponía, una vez más, otro proceso de 'reducción' hacia la condición de campesino pobre".

A opressão colonial, denunciada por Melià (1991/1986/1997), foi efetivada a partir do momento em que se instauraram os repartimentos dos índios, essa política colonial se deu para que os encomenderos pudessem explorar a força de trabalho indígena. De acordo com Haubert (1990), esse processo provocou várias rebeliões contra os "colonizadores cristãos". O autor afirma que no período de 1537 a 1616 se registraram mais de vinte e cinco revoltas contra os conquistadores. Um traço característico desse período histórico foi o surgimento de manifestações de caráter "messiânico" e "profético" contra a dominação.

Ao serem subjugados e angustiados pela feroz dominação, algumas tribos de índios da etnia Guarani se apegaram as religiões de salvação, esse processo é semelhante a de muitos povos oprimidos - o caso do povo judeu é emblemático nesta questão. Pois, é de conhecimento público, por exemplo, que Jesus de Nazaré predisse a queda dos maus, justiça para os pobres, o fim da miséria e do sofrimento, reunião com os mortos e um novo reino dos céus.

Haubert (1990) esclarece que, os traços da pregação dos nativos eram intrinsecamente pagãos, por mais que as crenças tradicionais fossem alteradas, a pregação dos "messias indígenas" se apresentava com força revigorada, buscando recuperar a felicidade ancestral que fora usurpada pelos conquistadores. Os movimentos rebeldes de indígenas com as características "pro- 
féticas" eram direcionados contra os estrangeiros. Os chefes dessas rebeliões eram na maioria das vezes caciques e xamãs, ou seja, homens que foram os mais humilhados pela opressão cristã.

Haubert (1990:160) descreve um desses movimentos em San Ignácio, por exemplo, os jesuítas decidiram tirar as concubinas de Miguel Altiguaye, cacique poderoso e respeitado, por eles nomeado como capitão geral da redução. $\mathrm{O}$ cacique mencionado proclama que os padres são "alcoviteiros" e ri das ameaças do inferno, "onde conta se divertir". O autor expõe que, o cacique Altiguaye se autoproclamou padre e começou a realizar cerimônias religiosas em sua choupana, imitando o rito católico. Vestido com uma alva e uma murça de penas multicores rezou a missa a sua maneira, a hóstia católi$\mathrm{ca}^{6}$ fora substituída por uma torta de mandioca e o vinho foi trocado pela "chicha ancestral" (bebida fermentada de mandioca) servida numa cabaça pintada de várias cores; falava entre os dentes e mostrava a torta e a chicha aos assistentes, consumiu tudo; finalmente fez mil cerimônias e foi objeto de grande veneração (Haubert 1990:160-161).

Melià (1991) destaca que as rebeliões arrancadas da tradição religiosa indígena, em que os índios ao se sentirem ameaçados, se manifestaram através de gestos e palavras também religiosas. Na expressão de Haubert (1990:160) seria uma batalha épica de "Messias contra Messias".

Haubert (1990) afirma que uma das mais significativas rebeliões, com esse caráter "profético", contra a opressão colonial foi a liderada pelo cacique Oberá (1597). Nessa revolta, os ameríndios comandados por Oberá cantavam e dançavam, ininterruptamente, durante vários dias. Os insurgentes usaram como bandeira de luta o questionamento acerca do "sacramento" católico do batismo, logo, eles passaram a "desbatizar" os autóctones que haviam sido batizados pelos cristãos, retiravam-lhes simbolicamente os nomes de batismo atribuídos pelos europeus, substituindo-os por novos nomes, conforme a tradição e no dialeto nativo. Esses, e outros levantes, foram movimentos de libertação contra a escravidão colonial e a opressão cristã, ao mesmo tempo a reafirmação, por parte dos nativos, de seu modo de ser tradicional. Que na crítica a religião do dominante encontrava sua expressão maior. Melià (1991) afirma que talvez, o povo Guarani em épocas anteriores à da colonização pudessem ter sentido, as vezes, a terra que habitava assolada por catástrofes naturais, como inundações, as secas, as enfermidades, as distensões internas, os ataques de outros povos. Mas, de acordo com o autor, não resta nenhuma dúvida que a maior tragédia que enfrentaram foi o da dominação, sob o julgo dos colonizadores, como um sistema que lhes retirou a liberdade (Melià 1991:17).

$\mathrm{O}$ autor entende que:

[...] no hay duda que las crisis de estos y más terribles males es la dominación colonial que como sistema le quita la libertad. Incluso las reducciones jesuitas, con su declarado intento de libértalos de la encomienda y del servicio personal, no eran sino espacios de libertad redu- 
cida donde el "modo de ser religioso" tradicional se veían desacreditado, ridiculizado y hasta físicamente perseguido. (Melià 1991:17)

Haubert (1990) explica que a entrada dos jesuítas no mundo guarani esteve acompanhada durante anos de uma verdadeira "guerra de messias". Se bem que os jesuítas, de acordo com Melià (1991:17):

[...] entro en un relativo diálogo con el pueblo guaraní cuando se trataba de comunicación lingüística y de ciertas concepciones de la vida económica y política, el antagonismo en el campo religioso, tanto en el campo de las creencias como en el de la expresión ritual, fue total.

O que podemos constatar, a partir das informações elencadas, é que a resistência dos nativos se deu em diversos campos: em revoltas armadas, em manifestações simbólicas, em alianças ofensiva e defensiva, etc. Haubert (1990) assegura que o Paraguai Colonial também foi durante séculos a terra da "eleição de messias" e de "profetas indígenas". Esse autor explica que em nenhuma outra região se pode constatar tantos movimentos de libertação tendo como base a mística. Os movimentos se multiplicaram a partir do momento em que os conquistadores estabeleceram a sua dominação e jogaram decisivamente no intuito de destruir a cultura dos povos originários.

Esses fatos relatados explicam o desespero que se apoderou dos silvícolas, alquebramento esse, assim descrito por Melià (1991:17-18): "Esta desesperación los habría animado a escuchar a los profetas que se levantaban entre ellos y que les ofrecían como solución la huida hacia la tierra - sin - mal o la venida próxima de una edad de oro".

O processo de aculturação empreendido nessa relação entre europeus e o povo Guarani, veremos a seguir.

\section{A SUBSTITUIÇÃO DA RELIGIÃO INDÍGENA PELA RELIGIÃO CRISTÃ}

Melià (1991) assevera que tanto na área de dominação colonial, propriamente dita, quanto nas áreas de missões (reduções) ${ }^{7}$ foi se processando gradual e firmemente a substituição da religião autóctone pela religião cristã. Um fenômeno cujo alcance e valor não se podem medir, mas que teve certamente mais implantação exterior que de aculturação participada. Melià (1991) não nega a autenticidade das conversões dos nativos, nem a verdade de suas novas expressões rituais, tão pouco discute a profundidade da vivência cristã inclusive em suas manifestações místicas entre os índios da etnia Guarani, nem a profunda religiosidade paraguaia. Pois, de acordo com o autor, esse processo seriam derivações que se separam da experiência religiosa do Guarani tribal, e que devem ser tratados especificamente como fenômeno de religiosidade popular.

Uma fonte importante para esclarecer esse processo, de busca da compreensão da religiosidade Guarani, é uma leitura atenta das cartas, informes e crônicas dos primeiros tempos da colonização. Cadogan (1992) descreve em um estudo antropológico a experiência religiosa guarani, que tem sido 
praticada por mais de um milênio nessa região do cone sul da América Latina, por gerações e gerações de homens e mulheres.

Para Cadogan (1992) a experiência religiosa segue sendo o signo que dá sentido a vida de muitas pessoas. Em relação à religiosidade Guarani desde a gênese da colonização, diversos autores descrevem a importância desta prática nessa sociedade. No ano de 1594, o padre Alonso Barzana (1970) já havia captado alguns aspectos fundamentais da religião Guarani. Esses textos, se despojarmos de suas concepções mais preconcebidas, possibilitará entender os elementos mais significativos da religião praticada pelos guaranis naquele contexto.

Melià (1991:23) descreve, também, a visão de um missionário sobre a primeira síntese da religião indígena: "Es toda esta nación muy inclinada a religión, verdadera o falsa, si los cristianos los hubieran dado buen ejemplo y diversos hechiceros no los hubieran engañado, no sólo fueran cristianos, sino devotos". Melià (1991) esclarece que outra síntese histórica da religião Guarani, na visão missionária, é a que oferece Antônio Ruiz de Montoya, que apresenta ao mesmo tempo uma defesa dos indígenas em relação aos ataques que sofriam dos encomenderos e dos bandeirantes paulista. Porém, no que tange ao aspecto religioso, a obra de Montoya, mantém uma visão conservadora, principalmente em relação aos "feiticeiros", aos quais o autor qualificava de "diabólicos".
Melià (1991) destaca a relativa incapacidade que repetidamente tem mostrado os missionários para entrarem em diálogo com o "espírito" das sociedades indígenas, que é acentuadamente mística, como é a sociedade Guarani, esta questão representa um problema teórico de certa importância. $\mathrm{Na}$ realidade seria problema sociológico e antropológico, que se expressa no caráter da não compreensão por parte dos jesuítas do aspecto central ocupado pela religião e, por conseguinte, das relações sociais da constituição dos grupos indígenas.

No aspecto antropológico, em muitos momentos, os jesuítas buscaram relativizar sua ação em relação a determinados elementos da prática cultural dos ameríndios. Porém, no campo religioso sob a hegemonia cristã, evidenciou-se a lógica do etnocentrismo europeu, que consistiu fundamentalmente em isolar uma característica da sua cultura e elevá-la à condição de definidora da "natureza humana".

De acordo com Rodrigues (1984:150), "[...] tal operação se faz sempre de modo a reservar para a cultura classificadora o lugar mais confortável, pois a característica isolada, considerada universal e inevitável, está acima de qualquer discussão". Na particularidade do Paraguai Colonial, devido à força da colonização, os jesuítas buscaram impor radicalmente a visão de mundo "cristã", fundamentada nos dogmas e nos ritos da igreja e a imposição da "moral cristã" desvelada, por exemplo, na proibição da antropofagia e na imposição do casamento monogâmico. 
Nimundajú (1987) afirma que um traço característico e fundamental para a compreensão da cultura desse grupo étnico é a "palavra". Para o Guarani, a "palavra" tem uma grande representação simbólica que constitui a sua visão de mundo, esse traço cultural capacita-o a qualquer diálogo. $\mathrm{Na}$ visão etnocêntrica da sociedade europeia, principalmente do missionário católico, essa singularidade cultural foi interpretada como uma predisposição "natural" as questões espirituais. Logo, esta "tolerância" se explicaria, dentro do eurocentrismo, pelo estágio "primitivo" dos indígenas. Curt Nimundajú (1987:14) esclarece: "[...] aunque naturalmente el guaraní en lo íntimo de seu ser, esté tan convencido de la verdad de su religión como el cristiano más fervoroso, nunca es intolerante".

A preocupação teórica, ao desenvolver a análise, tem por objetivo a compreensão das relações sociais que se desenvolveram no Paraguai, entre os jesuítas, os guaranis e os conquistadores espanhóis. O entendimento aprofundado dessas relações está entrelaçado na trama da constituição da sociedade colonial. Ao revelar a importância da "palavra" para a cultura guarani, manifestar-se aspectos significativos dessa formação social.

De acordo com Melià (1991:23): “ [...] para o Guarani a palavra é tudo. E tudo para eles é a palavra". Esta afirmação na visão eurocêntrica poderia ser atribuída a alguma influência da cultura ocidental, que tem sua matriz filosófica em Platão. Sem dúvida é através da palavra que os guaranis desvelam o seu modo de ser, que se manifesta, também, através de seus mitos, de seus cantos e de seus ritos. Neste sentido, sua cosmovisão tem a sua expressão máxima na palavra.

Melià (1986) alerta que não é fácil sistematizar o vocabulário Guarani, devido às várias subculturas, cada uma com suas características particulares. Há a necessidade de recorrer a textos particulares e buscar o valor semântico em um contexto mais global, verificando sua objetividade nas experiências de vida.

Partindo de uma análise da particularidade da cultura Guarani, Cadogan (1992) descreve o mito Mbyá - Guarani Ayvu rapyta (o fundamento da linguagem humana), esse estudo possibilita uma melhor compreensão da inter-relação dos diversos grupos da etnia guarani com o contexto universal. Cadogan revela que foi através da palavra lançada (O verbo) que Nanmandú (O Primeiro Pai) gerou o povo Guarani: "Antes de existir la tierra en medio de las tinieblas primigenias, antes de tenerse conocimiento de las cosas creó aquello que sería el fundamento del lenguaje humano, e hizo el Primer Padre Nanmandú que formara parte de su propia divinidad [...]" (Cadogan 1992:33).

Estas são as primeiras estrofes do mito Mbyá - Guarani Ayvu rapyta, que fora apresentado por Cadogan (1992), depois de ter escutado e registrado etnograficamente. O desenvolvimento do mito ratifica a importância da palavra na cultura guarani, possibilitando uma melhor compreensão do antagonismo, 
provocado nesse povo, quando foram subjugados pelos europeus.

Melià (1991) afirma que esses versos transcritos por Cadogan (1992), constituem uma das expressões mais importantes da religião Guarani. O dom da palavra por parte dos "padres divinos" e os diálogos participativo entre os mortais, marca o que é, e, o que pode ser um Guarani. O que podemos apreender dos estudos etnológicos, sobre a cultura em destaque, é que em todas as instâncias críticas desse povo. Como, por exemplo, a concepção, o nascimento, quando se recebe o nome, a iniciação, a paternidade, a maternidade, na enfermidade, na revelação da vocação chamânica, na morte e no "pós-morte"; todos esses momentos se definem em função de uma palavra única e singular, que dá substância à pessoa.

Toda essa reflexão poderia parecer uma gratuita transpiração platônica ocidental para o universo índio. Porém, atualmente existe uma farta documentação registrada por várias fontes etnográficas que destacam a centralidade desses elementos na cultura Guarani. Em síntese, o estudo etnográfico nos possibilita entender que é sempre em função da palavra inspirada que o Guarani cresce em sua personalidade, em seu prestígio e até em poder político ou mesmo em poder "mágico", ou em ambos, o que é mais comum.

Melià (1991) assegura que a educação do Guarani é uma instrução da palavra, pela palavra, porém, ele não é educado para aprender e muito menos para memorizar textos, mas, sim para escutar a palavra que receberá do "alto", geralmente, através dos sonhos. Para Melià (1986), o Guarani busca a perfeição de seu ser no esmero de sua fala, sua valorização e seu prestígio entre os membros de sua comunidade, e entre as comunidades vizinhas, vêm na medida pelo grau de perfeição e inclusive da quantidade de cantos e modos de dizer que possui. Logo, nós podemos ratificar pela análise de Melià que, a cultura analisada se fundamenta na oralidade, uma sociedade fundamentada em códigos sociais transmitidas por milhares de anos utilizando-se apenas da linguagem verbal. Que se defrontou, a partir do século XVI, com a sociedade europeia que se baseava além da oralidade, também na linguagem escrita, cujos códigos se expressavam em "leis" escritas. O seu próprio mito de criação estava expresso na elocução escrita da Bíblia Cristã.

Dentro dessa acepção, Melià (1991) esclarece que a sabedoria procede do desenvolvimento de sua palavra, esta por sua vez, na propriedade e intensidade de sua inspiração. É fácil verificar como é essencial para os índios das etnias Guarani a experiência propriamente religiosa, que nem todos conseguem no mesmo grau, mas que todos de um modo ou de outro ambicionam. Nesta direção Melià (1991:36) corrobora que: "En potencia, cada Guarani es un profeta - y un poeta".

Manifestada no plano ritual e no plano cerimonial a religião se promulga, também, através de uma homília mística que em sua origem emerge o modo de ser Guarani, onde as relações sociais estão entrelaçadas à sua cosmovisão, 
numa prática social da reciprocidade. A compreensão da prática social da reciprocidade entrelaçada contraditoriamente a práxis do conquistador europeu em sua lógica mercantil, possibilitará abarcar a singularidade das relações que constituíram e instituíram o imaginário social no Paraguai Colonial.

$\mathrm{Na}$ cultura dos índios da etnia guarani, de acordo com Melià (1991), a palavra original é caracterizada pela palavra que conta os mitos, palavra que significa a reciprocidade de saber dar esse grande dom que são as palavras. Para Melià, palavras ritualizadas e palavras profetizadas são formas de comunicação e intercâmbio de mensagens.

Em 1914, o antropólogo Curt Nimuendaju transcreveu em idioma Guarani o que denominou de: As lendas da criação e destruição do mundo como fundamentos da religião dos Apapocúva - Guarani (1987). É uma tarefa difícil oferecer um resumo do mito mencionado. Mas, para uma compreensão melhor do leitor, é importante descrever a visão de mundo Guarani, no sentido da apreensão de aspectos estruturantes de sua cultura, fato indispensável para revelar as complexas relações sociais que se processaram na Província do Paraguai.

Nimuendajú (1987) assevera que na mitologia a figura central é "Ñande Ru Vusu” (Nosso Grande Pai), que veio primeiro e se deixou conhecer no meio da escuridão originária, em seu peito havia uma luz como o sol. No mito, ele dá à terra seu princípio, colocando-a sobre firme suporte. $\mathrm{Na}$ alegoria o "Grande Pai" é o "conhecedor das coisas" e encontra uma mulher, que os índios dessa etnia denominavam de "Nuestra Madre". Os dois se casam, a "Nuestra Madre" fica grávida de gêmeos. "Ñande Ru Vusu” (Nuestro Padre), enojado, abandona "Nuestra Madre" na terra, saindo de cena, para voltar apenas no final, quando se faz presente na liturgia. A mãe grávida se põe a caminhar em busca do marido, porém é devorada por tigres; dessa relação nascem os gêmeos, por conseguinte órfãos. Os gêmeos convivem primeiro na casa dos tigres, mas eles se vingaram dos assassinos de sua mãe. O primeiro dos gêmeos foi denominado irmão maior e o segundo irmão menor, ambos saem para caminhar. Eles tentam recompor a sua mãe a partir de seus ossos, porém não conseguem, e a morte está definitivamente instalada na terra (Schaden 1976:830-841). De acordo com Schaden (1976:841) "são estes heróis que 'Guaranizaram' o aspecto do mundo, fizeram com que o mundo fosse Apapocúva-Guarani, tanto em sua natureza como na ordem social e cultural"s.

Retomando ao mito da criação Apapocúva-Guarani, os "heróis" continuam a sua caminhada, sempre em marcha, provocando e produzindo típicas situações da cultura: eles dão nome às frutas, roubam o fogo dos corvos, encontram outros semelhantes, acham os inimigos e os futuros cunhados. Por fim, se encontram de novo com o pai, mediante a dança ritual e ao som do maracá. O pai lhes deixou o que traz entre as mãos: seus atributos de xamã; e posteriormente se esconde de novo. A parábola prossegue afirmando que a terra está ameaçada; a obscuridade com 
seus morcegos pode cair sobre todos e o tigre azul os quer devorar. Entretanto, "Nuestro Padre" fez a pessoa de Tupã, que ao mover-se pelo céu provoca trovões e relâmpagos. $\mathrm{O}$ discurso mítico revela a visão de mundo desse povo, promulga traços de sua cultura, que se manifesta socialmente na dança, como um ritual que desemboca no encontro do Xamã com "Nuestro Padre" que lhes revela o caminho procurado. O caminho conduz a casa de "Nuestra Madre" onde não falta fruta, nem chicha para beber. É a festa (Schaden 1976:830-841).

Melià (1991) esclarece que o mito dos gêmeos é comum a todos os índios da etnia Guarani, da costa Atlântica até a Cordilheira boliviana. Apesar de algumas expressões que provavelmente registram preocupações mais modernas.

Outro aspecto importante da cultura analisada está relacionado à estreita ligação do Guarani com a terra. Melià (1991) afirma que em estudos arqueológicos nos sítios onde teriam habitado esse grupo étnico, sobretudo nas análises dos pedaços de cerâmicas encontrados revelam informações importantes.

Os estudos mencionados por Melià (1991:64) corroboram que, o Guarani é um povo cujo raio de ação abarca uma grande geografia com migrações eventuais a regiões muito distantes e com deslocamentos frequentes dentro de uma mesma região. Não são propriamente nômades, mas, de acordo com o autor, são colonos dinâmicos. Melià e Temple (2004:71) esclarece que:
[...] os Guaraní saben que el tekoa no es sólo lugar natural; también es el techo. No es pura técnica agrícola; es más apropiación técnica de un lugar por el conjunto de los que están unidos bajo el mismo. El tekoa viene a ser el espacio y las técnicas adaptadas a la naturaleza de los que comparten la misma unidad.

Os índios da etnia guarani ocupam terras com características ecológicas constantes; de fato, as terras mais aptas para o cultivo de maiz, mandioca, milho, batata, porongos e cabaças. Essas terras oferecem um horizonte ecológico bem definido, cujos limite dificilmente são quebrados. A mitologia guarani explícita a profunda ligação desse povo com a terra, como descreve Melià (1991:68):

El fundamento de la tierra Guaraní acaba siendo de este modo, la fiesta, donde se comparte la alegre bebida de la chicha: kawi, fruto de la tierra y del trabajo de muchos, unidos en minga (mutirão): potyrõ, donde también el hombre se hace palabra divina y esa palabra es compartida por todos. Donde hay una fiesta guaraní, ahí está en fin de cuentas el centro de la tierra y la tierra buena y perfecta a la que se aspira.

Um traço significativo da cultura desse povo é a linguagem dos sonhos e visões. Ao descrever essa particularidade, o leitor poderá ter uma melhor compreensão de como vai se constituir a construção da psique do índio reduzido nas missões, em síntese dialética com os dogmas e os ritos do cristianismo imposto pelos jesuítas. Como esclarece Marx (Apud Ianni 1984:146): "[...] A bem dizer, na história passada é um fato perfeitamente empírico que, 
pela transformação de sua atividade em atividade universal, os diversos indivíduos foram cada vez mais submetidos a um poder que lhes é estranho [...]".

Melià (1991) afirma que assim como outros índios da família tupi-guarani se guiam pelos sonhos, o conteúdo latente de sua psique emerge na prática social ritualizada. $\mathrm{O}$ xamã na sociedade Guarani representa o modelo ideal de pessoa, tendo nos sonhos uma de suas principais atividades; logo, são guiados pelos sonhos.

O etnógrafo Curt Nimundajú (1987:34) constatou o fenômeno e a grande importância do sonho entre os Apapokúva um subgrupo da etnia Guarani: “[...] se refiere a las experiencias del alma en el sueño, concuerdan los Apapokúva con todos os demás indios que se trata de sucesos reales, que pueden influir muy significativamente en el curso de vida de las personas".

Os elementos apresentados pela etnologia contemporânea - a palavra, o sonho e a religião - são algumas categorias antropológicas altamente pertinentes, quando se trata de analisar e compreender a produção social de um determinado grupo indígena. Porém, muitas das análises partem de um referencial epistemológico sistêmico e funcional, cuja função da palavra, da religião e do sonho seria apenas de manter a coesão social da sociedade analisada. Outro grupo de etnólogos parte de referenciais estruturais, cuja estrutura elementar permanece a-histórica, e a forma manifesta, o rito, o xamã, a festa, o som do maracá - vem no sentido de expressar as estruturas elementares que permanecem latentes. Muitas análises colocam as sociedades indígenas apartadas e isoladas da totalidade. Como se essas sociedades estivessem imunes às interferências externas. Apresentam as sociedades indígenas hipostaziadas, petrificadas, como se fossem sociedades sem história.

O recurso que possibilita lançar uma luz nas relações sociais produzidas a partir do processo de dominação europeia no Paraguai e, por conseguinte, esclarecer as relações econômicas e sociais a partir da conquista do território é a história. Pois, nas análises sistêmicas funcional e estrutural deixam, ou deixaram completamente, de lado a história, considerando-a uma coisa acessória, sem qualquer vínculo com a marcha da humanidade. Para entender os fundamentos epistemológicos das análises elencada, Marx (Apud Ianni 1984:147) traz a seguinte contribuição: “ [...] Por isso a história deve sempre ser escrita de acordo com uma norma situada fora dela, a produção real da vida aparece como não sendo histórica, enquanto o que é histórico aparece como separado da vida ordinária, como extra supraterrestres". Ao reconstituirmos os traços da cultura Guarani buscamos ressaltar essa historicidade e, dialeticamente, a dinâmica de sua transformação.

\section{CONSIDERAÇÕES FINAIS}

A palavra, a terra, o sonho e a religião não se explicam por si só, são elementos que possibilitam entender as teias de relações sociais da sociedade paraguaia do período colonial. Esses ele- 
mentos possibilitam a compreensão de como se deu a síntese dialética da cultura originária em relação contraditória com a cultura europeia. Partindo de questões de caráter universal e com a utilização de recursos históricos e antropológicos, procuramos conduzir uma reflexão filosófica mais geral. As análises arroladas no artigo não concernem somente ao patrimônio de uma sociedade particular. Mas, parte do principio universalizante na ótica descrita por Melià e Temple (2004:11) "[...] hay que poner de relieve y revelar lo que desde los orígenes de la humanidad permanece intangible y primordial en todas las comunidad del mundo: las matrices de los valores humanos".

Porém, esses valores não estão petrificados e estanques. São construídos e instituídos no devir de processos históricos, portanto, o mundo sensível não é um objeto petrificado, e muito menos um objeto dado diretamente por toda a eternidade, e sempre semelhante a si mesmo. Logo, é produto da indústria dos homens, do estado e da sociedade. Logo, a formação social do Paraguai é, assim como de toda América Latina, um produto histórico resultado da atividade várias gerações. Marx esclarece que nesse processo, a geração do presente herda a herança cultural das gerações passadas e: " [...] cada uma iça sobre os ombros da precedente, aperfeiçoa sua indústria e seu comércio, e modifica seu regime social, em função da transformação das necessidades" (Marx apud Ianni 1984:151).

O esforço de captação das linhas gerais da discussão acerca da cultura dos índios da etnia Guarani em seus traços mais característicos como a linguagem, a religião e o sonho, decorrem no sentido de pensarmos em cultura como dimensão do processo social.

Neste sentido, Santos (1986:46) esclarece que: "[...] nem cultura é a mesma coisa lá e aqui, nem seu significado é igual em ambos os casos. Apenas nesse sentido de ser a dimensão do processo é que se pode falar igualmente em cultura". Como se tratam de sociedades com características que as diferenciam bastante, os conteúdos do que é cultura, a dinâmica da cultura, a importância da cultura, tudo isso deve variar bastante.

As considerações expostas desvendam que as sociedades indígenas mantinham uma interação crescente com as diversas etnias que habitavam a região do cone sul da América Latina, anterior ao período colombiano. Após a conquista manteve relações com a sociedade colonial, posteriormente com a sociedade nacional. Em todos esses períodos históricos, os Guarani participaram de processos sociais comuns, partilharam de uma mesma história com os estrangeiros. Nesse processo sua cultura mudou de conteúdo e de significado. Podendo, em muitos momentos desse processo se expressar como traços de resistência a sociedade que as quer subjugar, tomar suas terras e colocá-las sob controle. Porém, foi inevitável que os nativos incorporassem novos conhecimentos para que pudessem melhor resistir a opressão, que a sua cultura também se transformasse para que a sociedade sobrevivesse. 
Assim, ao analisar a cultura guarani implicou descortinar o processo social concreto: as lendas e crenças, a linguagem, o sonho, as festas ou jogos, costumes e tradições. Esses fenômenos não dizem nada por si mesmos, como esclarece Santos (1986:47): “[...] eles apenas dizem enquanto parte de uma cultura, a qual não pode ser entendida sem referencia à realidade social que faz parte, a história de sua sociedade". A ideia que tem a centralidade nessa análise é a de processo, pois é comum em diversos campos teóricos que a cultura seja pensada como algo estático, parado, petrificado.

Queremos afirmar que nada do que pertence à cultura pode ser estanque, porque ela se insere em uma realidade onde a mudança é seu aspecto fundamental. A visão exposta é antagônica a visão dominante que apresenta a cultura guarani como se fosse um produto, uma coisa com começo, meio e fim, com características definidas e um ponto final. Em muitos casos o etnólogo extrai da experiência histórica do povo Guarani produtos, estilos, formas, mitos e constrói-se com isso um modelo de cultura. Essas construções podem servir para fins políticos, como, por exemplo, tornar ilustre a imagem de uma potência dominadora como ressaltou Santos (1986).

Ao mesmo tempo, é comum que os interesses dominantes de uma sociedade expressem uma definição de cultura das sociedades indígenas que seja de seu agrado. Vale a pena ressaltar que nem todos esses modelos se esgotam nesses fins. Nesta análise, a cultura é a dimensão da sociedade que inclui todo o conhecimento num sentido ampliado e todas as maneiras como esse conhecimento é expresso. Logo, é uma dimensão dinâmica, criadora, ela mesma em processo, uma dimensão fundamental da sociedade.

\section{NOTAS}

${ }^{1}$ A ordem foi fundada em 1539, porém a história da Companhia de Jesus não pode ser compreendida sem o entendimento da trajetória do seu fundador Inácio de Loyola (1492-1556) e, consequentemente, o contexto histórico em que estava inserido. Inácio de Loyola nasceu em Azpétia (Espanha), de uma família de soldados. Viveu na sua juventude a vida promíscua e agitada dos fidalgos e militares do seu tempo. Em 1534, Inácio de Loyola torna-se mestre em artes e, naquele mesmo ano, aglutina em torno de si um grupo de "doutores" da Universidade de Paris. Dentre eles estavam Pierre Favre, Francisco Xavier, Diego Lainez, Alfonso Salmeron, Paschase Broët, Jean Cadure, Simão Rodrigues, Claude Lê Jay, Nicolau Bobadilha. Foram esses dez homens os fundadores da Companhia de Jesus, tendo como ponto central de sua organização a obediência devida ao "preposto geral", o voto de pobreza e a renúncia a toda forma de cerimonial monástico.

${ }^{2} \mathrm{~A}$ área de jurisdição (formal) da Província do Paraguai no período delimitado (1558 1767) abrangia limites territoriais mais extensos que os atuais. O Paraguai possuía jurisdição sobre os atuais Estados brasileiros do Paraná, Santa Catarina, Rio Grande do Sul, Sul de Mato Grosso (atualmente Mato Grosso do Sul) e parte do Pantanal Mato-grossense, subindo a bacia do Amazonas.

${ }^{3}$ No devir histórico da humanidade ocorreram encontros de culturas distintas, essas confluências foram permeadas pela alte- 
ridade. A antropologia emerge no século XIX, em quanto campo do conhecimento sistematizado, no momento em que ocorre em dimensão global a convergência e o choque de diversas culturas distintas. Logo, a antropologia e os antropólogos buscaram criar conceitos para explicar esses fenômenos. Vários conceitos foram criados para explicar como se deu, ou se dá, a relação entre os europeus e as sociedades autóctones por eles invadidas e colonizadas, como por exemplo: relativismo cultural, fricção interétnica, mudança cultural, assimilação, etc. $\mathrm{O}$ conceito que orientou esse artigo no sentido de iluminar a relação estabelecida entre os Europeus e os índios da etnia Guarani foi o conceito de aculturação. Esse conceito não é fundamentalmente sinônimo de mudança cultural. Já que toda cultura muda. Não há cultura que permaneça estanque, que não se transforme, pois, a cultura é um eterno devir. Entretanto, algumas culturas mudam mais rápida, outras vão mais devagar. De acordo com Cuche (2012:116): “[...] não se pode confundir aculturação e 'assimilação'. A assimilação deve ser compreendida como a última fase da aculturação, fase aliás raramente atingida. Ela implica o desaparecimento total da cultura de origem de um grupo e na interiorização completa da cultura do grupo dominante. "No campo da antropologia ocorreu, e ocorre ainda na atualidade, o debate acerca de dois grandes arquétipos teóricos (funcionalismo e culturalismo) sobre o contato entre populações indígenas e a sociedade nacional constituída após o período colonial. $O$ conceito aculturação tem sua origem no culturalismo americano, e o conceito que se contrapõe a este é o da mudança social, mais afeito ao funcionalismo britânico. Roberto Cardoso de Oliveira se contrapõe, também, ao conceito da aculturação em seu livro: Do indio ao bugre: o processo de assimilação dos Terena (1976). Cardoso registra nesse trabalho a noção de assimilação, que se opõe à aculturação (que seria um momento do processo de assimilação, cujo outro momento seria a perda da identidade). No livro citado, Cardoso não defendia a assimilação, absolutamente, mas apenas usava o conceito para mostrar que os Terena não estavam assimilados $\mathrm{e}$ nada os levava à assimilação, porque, embora eles perdessem a cultura, a identidade tribal está cada vez mais forte. Essa é a tese do livro de Cardoso. Para explicar esse processo Cardoso cunhou o conceito fricção interétnica para se contrapor ao conceito de aculturação. Neste artigo sobre a cultura guarani é utilizado o conceito de aculturação no sentido exposto por Cuche (2002:114): “A aculturação é o conjunto de fenômenos que resultam de um contato contínuo e direto entre grupos de indivíduos de culturas diferentes e que provocam mudanças nos modelos (patterns) culturais iniciais de um ou dos dois grupos."

${ }^{4}$ A conquista e a colonização do Paraguai, no decorrer do século XVI, anularam os direitos dos guaranis sobre as terras. Os reis católicos pautados na Bula Papal de 1493, declararam em 1519 o seguinte: "Por donación de La Santa Sede Apostólica y otros justos y legítimos títulos, somos senõres de Las Índias Occidentales, Isla y Tierra firme del mar océano, descubiertas e por decubrir y están incorporadas en nuestras Real Corona de Castilla". A ocupação das terras do Paraguai exigiu a instituição de um aparato legal denominado Leyes de Índias. Como evidenciamos no fragmento acima citado, essa legislação buscava preservar os interesses do Estado Espanhol sobre a América. Ver mais: Compilación de las Leys de Índias. Ley I, Título I, Libro III. V edición, Madrid, 1841, in Quevedo, J. 2000. Guerreiros e Jesuitas na Utopia do Prata, pp. 65-66.. Bauru: Edusc.

${ }^{5}$ Encomienda: historicamente a origem da prestação obrigatória de serviços pelos in- 
dígenas provém desde as capitulações de Colombo. Em um processo denominado de "repartimentos", onde as populações indígenas foram distribuídas aos colonos, quando da primeira invasão espanhola. $\mathrm{Na}$ singularidade paraguaia, a legislação espanhola que tratava especificamente da questão indígena estabeleceu duas espécies de prestação de serviços (nos termos semânticos da escravidão) tendo como base à "encomienda" que seria a "prestação de serviço pessoal" e a "Mita" que estava relacionada ao pagamento de tributos. Para o seu estudo é fundamental a consulta Leys de Indias Ley I, Titulo I, libro III. V. edicion. Madrid.1841. As principais obras historiográficas, essenciais à compreensão da Encomienda: Chaunu, P. 1969. A América e as Américas. Rio de Janeiro: Cosmos. Gadelha, Regina Maria A. F. 1980. As Missões do Itatim. Rio de Janeiro: Paz e Terra. Astrain, A. 1996. Jesuitas, Guaranies y Encomenderos: historia de la Compañia de Jesús em el Paraguay. 2. ed. Assunción: CEPAG-FPMN. Cortesão, J. 1951. Jesuitas e Bandeirantes no Guairá (1549-1640). Rio de Janeiro: Biblioteca Nacional. 1952. v. II. Jesuitas e Bandeirantes no Itatim (1595-1760). 1969. V. III. Jesuitas e Bandeirantes no Tape (1615-1641). 1966. Raposo Tavares e a formação territorial do Brasil. Lisboa: Portugália. 1952-1970. Manuscritos da Coleção de Angelis. Rio de Janeiro: Biblioteca Nacional, Divisão de Obras Raras e Publicações.

${ }^{6}$ Pequena rodela muito fina, feita de pão ázimo, que é "consagrada" durante a missa católica e oferecida aos fiéis no rito comunhão.

${ }^{7}$ Redução Jesuítica, de acordo com Quevedo (2000) as reduções foram a concentração de índios em pequenos povoadas, para convertê-los à fé da Igreja Católica reformada, conforme estipulado pelo Concilio de Trento (1545 - 1563). As reduções eram, portanto, povoados exclu- sivamente de indígenas, principalmente da etnia Guarani. Com igrejas, residência de índios e que devido às hostilidades de encomenderos e bandeirantes impunham um caráter itinerante ao empreendimento. A produção econômica das reduções se fundamentava em dois elementos: 1) a propriedade coletiva de todos os meios de produção (o Tupambaé), que na linguagem indígena significa - a "terra de Deus", na qual se desenvolviam as atividades agropecuaristas, sob a direção dos jesuítas. $\mathrm{O}$ segundo elemento era a propriedade particular dos meios de produção (o Amambaé ou Avambaé), onde se praticava a atividade agrícola, por meio do trabalho familiar. As reduções disseminaram-se pelo Paraguai e pelo Rio da Prata, tendo como base legal as Ordenanças de Alfaro e alcançaram grande prosperidade e grandes contradições.

${ }^{8}$ Tradução Nossa.

\section{REFERÊNCIAS}

Barzana, A. 1970. Monumenta Peruana. Roma: Monumenta Missionum.

Cadogan, L. 1992. Ayvu Rapyta: Textos miticos de los Mbyá-Guarani Del-Guairá. Assunción: CEADUC-CEPAG.

Cuche, D. 2002. A noção de cultura nas Ciências Sociais. $2^{\mathrm{a}}$. ed. Bauru: EDUSC.

Haubert, M. 1990. Índios e Jesuitas no Tempo das Missões. São Paulo: Companhia das Letras.

Ianni, O. 1984. Marx: sociologia. $3^{\text {a }}$. ed. São Paulo: Abril Cultural.

Marx, K. 1978. Manuscritos Econômicos e Filosóficos e outros textos escolbidos. Coleção "Os Pensadores”. Tradução: José Carlos Bruni. $2^{a}$. ed. São Paulo: Abril Cultural.

Melià, B. 1997. Una Nación dos Culturas. $4^{\text {a }}$. ed. Assunción: CEPAG. 
.1986. El Guarani Conquistado y Reducido: ensayos de etnohistoria. Biblioteca Paraguaya de Antropología. v.V. Assunción: CEADUC.

.1991. El Guarani: experiência religiosa. Assunción: CEPAG.

Melià, B. e D. Temple. 2004. El don, la venganza: y otras formas de economía guaraní. Assunción: CEPAG.

Montoya, A. R. 1989. Conquista espiritual hecha por los religiosos de la Compañia de Jesús en las provincias del Paraguay, Paraná, Uruguay y Tape. Rosario: (s.e).

Nimundajú, C. 1987. As lendas da criação do mundo como fundamentos da religião Apapocúva - Guarani. São Paulo: Hucitec.

Oliveira, R. C. 1976. Do indio ao bugre: o processo de assimilação dos Terena; (prefácio de Darcy Ribeiro). 2. ed. Revisada. Rio de Janeiro: Francisco Alves.

Quevedo, J. 2000. Guerreiros e jesuitas: na utopia do Prata. Bauru: EDUSC.

Rodrigues, J. C. 1984. Antropologia e comunicação: princípios radicais. Rio de Janeiro: Espaço e Tempo.

Santos, J. C. 1986. O que é cultura. $5^{\text {a }}$. ed. São Paulo: Brasiliense.

Schaden, E. 1976. Les religions indigénes em Amérique du sud, in Encyclopédie de la Pléiad, histoire des religions. v.III. Paris: Gallimard.

Recebido em 17/02/2017

Aprovado em 07/03/2017 